\title{
Structural Capability of an Organization toward Innovation Capability
}

\author{
Susanne Balslev Nielsen \\ Associate Professor of Department of Engineering Management \\ Technical University of Denmark, Lyngby, Denmark \\ Mostafa Momeni \\ Assistant Professor of Management Faculty \\ Kharazmi University, Tehran, Iran
}

Received: Feb. 6, 2016 Accepted: March 12, $2016 \quad$ Published: April 1, 2016

doi:10.5296/jmr.v8i2.8987 URL: http://dx.doi.org/10.5296/jmr.v8i2.8987

\begin{abstract}
The scholars in the field of strategic management have developed two major approaches for attainment of competitive advantage: an approach based on environmental opportunities, and another one based on internal capabilities of an organization. Some investigations in the last two decades have indicated that the advantages relying on the internal capabilities of organizations may determine the competitive position of organizations better than environmental opportunities do. Characteristics of firms shows that one of the most internal capabilities that lead the organizations to the strongest competitive advantage in the organizations is the innovation capability. The innovation capability is associated with other organizational capabilities, and many organizations have focused on the need to identify innovation capabilities.
\end{abstract}

This research focuses on recognition of the structural aspect of innovation capability and proposes a conceptual framework based on a Qualitative Meta Synthesis of academic literature on organizations innovation capability. This is proposed for the development of the concept of innovation capability in the organizations and this paper includes an expert based validation in three rounds of the Delphi method. And for the purpose of a better appreciation of the relationship dominating the factors of the conceptual framework, it has distributed the questionnaire in Iranian companies of the Food industry. At last, this research proposed a direct relationship between Innovation Capability and Structural Capability. Also, it offers the 


\section{Macrothink

most important components and indices which directly influence and are related to the structural capability of innovation capability.

Keywords: Innovation Capability, Structural Capability, Managerial Capacity, Cultural Capacity, Communicational Capacity, Organizational Knowledge Capacity. 


\section{Introduction}

To maintain the survival of organizations in the competitive context of the world today, organizations have no way out except attaining a competitive advantage (Porter, 1980; Barney, 1991). In order to explain the competitive advantage in organizations, two viewpoints are to be considered: The first approach which is based on the Industrial Organization Theory (Bain, 1968) in Michael Porter's ideas regards attainment of competitive advantage as resulting from environmental opportunities and is called the Market Based View (MBV). The analytical instruments utilized in this point of view are analysis of the value chain, analysis of competitive forces, generic strategies, competitiveness, clusters, competitive advantage of nations, etc. (Porter, 1980). Another approach the issues of which became common in the strategic management literature since the publication of the article "Resource Based Theory" by Wernerfelt 1984 is called the Resource Based View (RBV). This viewpoint has been investigated and developed by other experts and the related models have been appraised in organizations (Barney, 1986). Numerous studies in the last two decades have indicated that the competitive advantage based on internal capabilities of organization is the best origin for generation of success (Crook et al., 2008). The capabilities approach constitutes an extension to the resource based perspective (Helfat et al., 2007). In this conception, resources change through the action of capabilities approach, while some capabilities may deal specifically with adaptation, learning, and change processes. All capabilities have the potential to accommodate change (Helfat et al., 2003). Capabilities refer to the firm's ability to alter the resource base by creating, integrating, recombining and releasing resources (Eisenhardt \& Martin, 2000). Also, many theorists have focused on the need to identify organizational capabilities and resources or strengths in relation to external opportunities and threats according to inside-out view of resource based approach in the firms (Bryson et al., 2007). So, capability translates to dynamic capability for Interaction of internal resources of organization with environmental opportunities (Teece et al., 1997-2009) and the innovation capability is one of most important dynamic capabilities that orientates the organization to adapting with environmental opportunities (Saunila et al, 2014). The innovation capability can be either a new product, a new service, a new technology, or a new administrative practice (Hage, 1999). This approach defines a capability for innovative organization as one that is intelligent and creative, capable of learning effectively and creating new knowledge (Lam, 2004).

An Investigation of scientific articles shows that most articles in the area of capabilities do not usually offer any recommendation concerning the procedures for management of the development of capabilities (Borjesson \& Elmquist, 2011). In the innovation literature, researchers have pointed to the lack of a comprehensive theory or model of innovation and the related capabilities with a capacity for organizational understanding (Khalil, 2002).

The food industry in Iran is not in an appropriate state regarding innovation indexes despite having a strong agricultural basis. Thus, the final survey of this study in Iran's food industry could contribute to the emergence of innovation in this industry. For this purpose, this research follows to find structural factors influential on innovation capability of organizations through a procedure with provision of a comprehensive model and the theoretical confirmation of the model. 


\section{Innovation Capability}

Innovation capability consists of internal reinforcement procedures and processes. This process is a key mechanism for stimulation, measurement, and reinforcement of innovation (Lawson \& Samson, 2001). Many authors consider innovative capabilities equal with being innovative or even innovative performance of aspects that could be quantitatively assessed (e.g. the number of inventions registered or the number of operations of a new product). Although these measures are useful pieces of information on the performance of the firm, they do not offer a picture of innovation capability of the firm. The concept of capability is not a performance parameter but it is an index of preparedness of the firm and the development through innovation forces (Borjesson \& Elmquist, 2011). This research believes innovation capability is a great ability to provide innovative services and products continuously through the organizational capabilities, capacities and competencies. This definition is utilized by some other researches (Saunila et al., 2014; Saunila \& Ukko, 2012; Sáenz et al., 2009; Lawson \& Samson, 2001). Innovation capability completes as the result of several relationships and communication among organizational, resources, qualifications, and connections with other organizations (Hii \& Neely, 2000) so the innovation capability increases the competitive advantage of the firms (Tidd et al., 2005).

\section{Research Method}

This research is descriptive and non-experimental and employs a qualitative research method. Data collection is obtained through the following two ways:

A. Qualitative Meta Synthesis of literature. The researchers reviewed most of valuable and scientific papers and articles in Innovation Capability field with critical consideration (Maxwell, 2013), so this research made a critical review on all of the articles that focused on innovation capability in the past decade. At last, the conceptual model proposed for the development of innovation capability in the organizations, and thus

B. Delphi method, for the theoretical confirmation of the conceptual framework (Boynton \& Zmud, 1984) of innovation capability, an expert panel formed in three rounds (first round by interview, 2 rounds by questionnaires). The panel include 20 innovation experts (Academic Scholars and Practitioners; which were elected as experts in organisational capabilities due to their research field or their Managerial role in an organisation with innovation as key business e.g. an entrepreneurship organisation; but also their availability).

C. Survey, for the purpose of a better appreciation of the relationship dominating the factors of the model confirmed in Delphi rounds, this research has distributed the questionnaire in 55 Iranian companies of the food industry. The major audience of the survey are the managing directors and deputies of these firms, and 43 firms have responded to the questionnaire. Some firms have completed more than one questionnaire the average of which is computed and only one representative of every firm is considered in the final appraisal. 


\section{Ml Macrothink}

The qualitative collected data (from both A and B) was coded (using open coding) and classified. Then the questionnaire data analysed by statistical analysis with Variance and Arithmetic Mean (Average in Statistics). The statistical measurements come out from five-step Likert questionnaire.

Table 1. Overview of the applied research design

\begin{tabular}{|l|l|}
\hline In this research: & Mixed method: Qualitative and Quantitative Methods \\
\hline Methodology & Qualitative Meta Synthesis, Delphi Panel, Survey \\
\hline Research Strategy & $\begin{array}{l}\text { Documentations, Critical Literature Review, Structured and Semi } \\
\text { Structured Interviews, Questionnaire Survey }\end{array}$ \\
\hline Data Collection & Open Coding and Statistical Analysis \\
\hline Data Analysis &
\end{tabular}

As illustrated in table 1; the general research design is a multi-method study. It consists of step one: the generation of a conceptual model of innovation capability through the critical review of other researches by qualitative Meta synthesis. In step two, a Delphi panel is set with innovation capabilities experts utilizing the snowball technic. Then, as the first round of Delphi, short structured interviews with individual experts. This was followed up by a second and third rounds of Delphi using a questionnaire. For data analyses of the answers, open coding (for literature review and open interviews) and statistical analysis (for structured interviews and questionnaire survey). Based on the prior knowledge experts of capability, we proposed a final conceptual model to describe and improve organisations innovation capability. Which consists of components and indices. In addition, for definition of the relation between factors, we employed the AMOS structural equation.

\section{Research Results}

This research focuses on the structural factors of Innovation Capability in organizations. The outcome of the Qualitative Meta Synthesis of literature, is a conceptual model; which was modified due to expert's comments in the rounds of the Delphi method. The first round was done by structured interviews, and we identified the components as figure 1 . Then at the second and third rounds, they confirmed components and indices as table 2 and table 3 . The statistical measurements come out from Likert (five-step Likert questionnaire) in the Delphi rounds. It should be emphasised that the agreement within the expert panel is significant. The scientific domination was as minimum $84 \%$ that was measured by some questions. It means that the data provided through the panel is very reliable for further studies and other researches and empirical applications. In addition, the participation of panel members has been rated as $90 \%, 85 \%$, and $85 \%$ in the first, second and third rounds respectively. 
Table 2. Delphi Results, Dimensions and Components

\begin{tabular}{|l|l|c|c|c|l|l|}
\hline \multicolumn{2}{|l|}{ Does Innovation Capability depend on: } & $\begin{array}{l}\text { Round } \\
1\end{array}$ & $\begin{array}{l}\text { Round } \\
2\end{array}$ & $\begin{array}{l}\text { Round } \\
3\end{array}$ & Result & Source \\
\hline Dimensions & Structural Capability & 4.7 & 4.2 & Yes & Approved & Literature \\
\hline & $\begin{array}{l}\text { Knowledge Based } \\
\text { Capacity }\end{array}$ & 4.5 & - & - & - & $\begin{array}{l}\text { Camerom } \\
\text { literature, but has } \\
\text { been broken down } \\
\text { to Organizational } \\
\text { Knowledge } \\
\text { Capacity due to } \\
\text { the expert's } \\
\text { comments }\end{array}$ \\
\cline { 2 - 7 } & $\begin{array}{l}\text { Organizational } \\
\text { Knowledge Capacity }\end{array}$ & - & 4.7 & Yes & Approved \\
\cline { 2 - 7 } & Managerial Capacity & 4.7 & 4.6 & Yes & Approved & Literature \\
\cline { 2 - 7 } & Cultural Capacity & - & 4.5 & Yes & Approved & Interview \\
\cline { 2 - 7 } & Communicative Capacity & - & 4.7 & Yes & Approved & Interview \\
\hline
\end{tabular}

Table 3. Delphi Results, Indices

\begin{tabular}{|c|c|c|c|}
\hline Component & Index & Delphi & Result \\
\hline \multirow{4}{*}{$\begin{array}{l}\text { Managerial } \\
\text { Capacity }\end{array}$} & Strategy And Goals & 4.6 & Approved \\
\hline & Management Style & 4.4 & Approved \\
\hline & Stability of Management & 4.1 & Approved \\
\hline & Resource Availability & 4.2 & Approved \\
\hline \multirow{3}{*}{ Cultural Capacity } & Flexibility & 4.4 & Approved \\
\hline & Diversity & 4.1 & Approved \\
\hline & Risk Acceptance & 4.4 & Approved \\
\hline \multirow{2}{*}{$\begin{array}{l}\text { Communicative } \\
\text { Capacity }\end{array}$} & Communication Network & 4.7 & Approved \\
\hline & Cooperation with others & 4.3 & Approved \\
\hline \multirow{4}{*}{$\begin{array}{l}\text { Organizational } \\
\text { Knowledge } \\
\text { Capacity }\end{array}$} & Organizational Learning & 4.7 & Approved \\
\hline & Knowledge Storage & 4.3 & Approved \\
\hline & Knowledge Absorption & 4.6 & Approved \\
\hline & Information system & 4.2 & Approved \\
\hline
\end{tabular}

\section{Discussion}

With reference to the summarized literature and the research paradigm of this study which is formulated on the systematic definitions of innovation, it is understood that innovation capability is dependent upon structural capability in the organization. The structural 
capability is very much dependent upon internal processes of organizations as managerial capacity, cultural capacity, communicational capacity and organizational knowledge capacity.

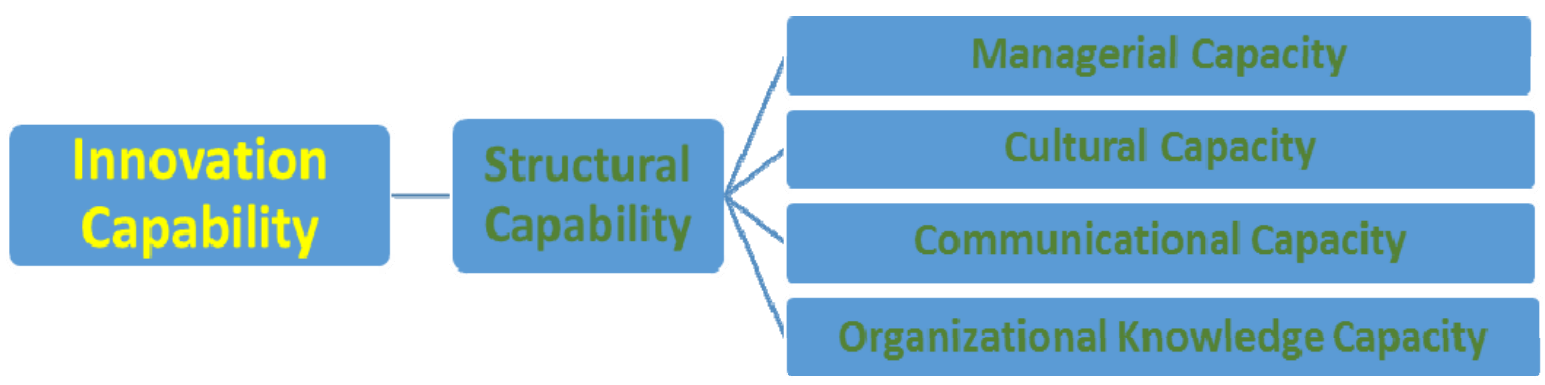

Figure 1. The Structural Capability of Innovation Capability

\subsection{Structural Capability}

Innovation capability completes as the result of several relationships and communication among organizational, resources, qualifications, and connections with other organizations (Hii \& Neely, 2000). Therefore, the innovation capability of a firm is not the result of one of its abilities but it flows from a collection of abilities and other capabilities, which means an internal potential for generation of new ideas, identification of new market opportunities, new services and products through resources and capabilities of a firm. Considering the literature reviews and the Delphi rounds, this research believes innovation capability has been dependent on structural capability in an organization.

Structural capability is effective in the provision of organizational innovation capability since organizations should take the most advantage of their internal organizational situation and structures for development of new capabilities and reconstruction of the existing capabilities (Colarelli O'Connor \& DeMartino, 2006). Structural capability states that in addition to operational dimension, the structural changes of an organization toward the establishment of a capability that causes the flow of the innovation capability in the organization plays a significant role for achieving success. Some define this as the capability for the formation of a stable structural mechanism for modification of all activities toward common goals for the purpose of an effect on the speed of innovation process through infrastructure for developmental projects (Guan \& Ma, 2003) and some others refer to it as a structural mechanism of an organization for realization of innovation (Lichtenthaler \& Lichtenthaler, 2009).

Of course, this research is of the opinion that structural capability is dependent upon four capacities in an organization: managerial capacity, cultural capacity, communicational capacity and organizational knowledge capacity which is based on the storage and generation of organizational knowledge and organizational learning.

Managerial Capacity: with the emergence of companies in the early twentieth century, many attractions have come up around the role and functions of managers (Chiesa el al., 
1996). The issue has been dealt with in different scientific areas such as operation theory utilizing scientific knowledge on production systems, vertical and horizontal assimilation of provisional chains. They claim that the management of firms are able to carefully plan and coordinate resources and capabilities of an organization (Zawislak et al., 2012). Structural changes of an organization toward establishing capabilities for the purpose of developing competitive superiority is understood only through managerial capacity (Zawislak et al., 2013). The innovation capability relates directly with managerial capacities such as planning an appropriate organizational structure, planning a mechanism for relationship with mainstream of an organization, multilevel management and a proper decision-making mechanism, use of innovation networks, budget and reward system based on innovation, strategic planning, and leadership style (Colarelli O'Connor, 2008). Also, studies show that there will be no improvement in the development of capabilities without an explicit and coordinated support by managers regarding the origin and outcome of capabilities (Borjesson $\&$ Elmquist, 2011). On the other hand, the management system which applies the innovation capability as a strategic capability for activating the cycle of innovation strategy and couples the existing trade with the strategic innovation system can achieve move success in the innovation capability (Kodama \& Shibata, 2014). Also, it is necessary to emphasize that integration and coordination among other capacities for the establishment or development of organizational innovation capability is carried out by the management of an organization (Lichtenthaler \& Lichtenthaler, 2009), this is combined in this study under the title of managerial capacity.

Cultural Capacity: cultural capacity is represented by the organizations which have structured flexibility into their organizational culture to embed and encourages teamwork, creativity, learning and collaboration which creates value collectively (Verma et al., 2014). Cultural capacity is the culture executed by a learning organization with the aim of creating a culture to contribute to a valued outcome by enhancing organization's ability and thereby boosting innovation capability (Hung et al., 2010). Emphasizing cultural facets which impart comprise management backing for inspiring employees to work together, search, interact, and seek support toward innovation will lead to acquisition of capacity resulting in innovation (Verma et al., 2014).

Communicational Capacity: innovative activity may arise from any part of the organization process such as organizational communication abilities, entrepreneurial ability, adaptability, etc. Also communicative capacity contributes strongly to innovation, especially in services and in organisational innovation. A communication channel is a structural characteristic that can be used by a decision unit to achieve successful innovation implementation within organizations (Fidler \& Johnson, 1984). The communicative capacity refers to organizational ability for networking and cooperating with other organizations (De Marchi, 2010).

Organizational Knowledge Capacity: one of the other most important components of innovation capability is the knowledge of organization which are accumulate in personnel and information systems of organizations and firms (Skiltere \& Jesilevska, 2013). Organizational knowledge refers to accumulated skills and expertise (Hefat et al., 2007) but many authors and theoreticians distinguish between exploration and creation of knowledge 
on the one hand, and exploitation of knowledge on the other (Bansal \& Bonger, 2007). Moreover, some believe that organization of knowledge processes takes place beyond the boundaries of firms (Cassiman \& Veugelers, 2006) and, of course, some authors have laid stress on the significant role of the combination of internal and external knowledge in the process of innovation. It is necessary to emphasize that restoration of the internal knowledge refers to generation of new knowledge within the firm and restoration of the external knowledge refers to the description of the acquisition of knowledge from outside sources (Lane et al., 2006). Exploitation of the internal knowledge is the description of the internal innovation and exploitation of the external knowledge refers to the transfer of knowledge to outside of the organization (Lichtenthaler, 2007). Also, exploitation of knowledge involves repetition of new methods in different situations and implementation of the internal and external programs in various circumstances since organizations are different by nature and for survival in environmental charges make different choices for utilization of their innovations. And it is to be emphasized that maintenance of internal and external knowledge is related to organizational processes and guarantees the constant transfer of knowledge through which the best start for exploration, maintenance, and exploitation of knowledge takes place (Zollo \& Winter, 2002). Also, in the maintenance of knowledge, an organization confronts the issue of integration or dependence of knowledge which is a reference to the likelihood of the combination of internal and external knowledge. Of course, the complementary nature of internal and external processes of knowledge requires coordination in the organization (Cassiman \& Veugelers, 2006). An organization needs reconstruction in its knowledge for boosting conformation ability or modifying environmental conditions earlier than competitors in order to be successful (Lichtenthaler \& Lichtenthaler, 2009). Absorption and maintenance of external knowledge for transfer to the organization should be considered seriously. Of course, for the purpose of gaining and having access to external knowledge, a firm should often provide for the transfer of a part of its knowledge to outside (Grant \& Baden-Fuller, 2004). In fact, the organizational knowledge capacity contributes to the revision of the source of innovation with the goal of surviving over time since the necessity for transfer and renewability of resources is considered a significant principle in dynamic capabilities (Lichtenthaler \& Muethel, 2012) and also because organizations should activity renew and rearrange their innovative processes over time (Helfat et al., 2007).

\subsection{Index}

All the theoretical concepts should be segmented into dimensions to understand their various aspects. And on the next level, dimensions should be broken down to components. Also, for certain empirical aspects of a subject, components should disintegrate to indices (Bhattacherjee, 2012). In this research innovation capability is the core concept of research, and the structural capability is the main dimension of innovation capability. Also, the main components and indices are listed in Table 4. 


\section{Macrothink}

Journal of Management Research

ISSN 1941-899X

2016, Vol. 8, No. 2

Table 4. Indices of Innovation Capability

\begin{tabular}{|c|c|c|c|}
\hline Concept & Dimension & Component & Index \\
\hline \multirow{13}{*}{$\begin{array}{l}\text { Innovation } \\
\text { Capability }\end{array}$} & \multirow{13}{*}{ Structural Capability } & \multirow{4}{*}{ Managerial Capacity } & Strategy And Goals \\
\hline & & & Management Style \\
\hline & & & $\begin{array}{l}\text { Stability of } \\
\text { Management }\end{array}$ \\
\hline & & & Resource Availability \\
\hline & & \multirow{3}{*}{ Cultural Capacity } & Flexibility \\
\hline & & & Diversity \\
\hline & & & Risk Acceptance \\
\hline & & \multirow{2}{*}{ Communicative Capacity } & Networking \\
\hline & & & Cooperation \\
\hline & & \multirow{4}{*}{$\begin{array}{l}\text { Organizational } \\
\text { Capacity }\end{array}$} & $\begin{array}{l}\text { Organizational } \\
\text { Learning }\end{array}$ \\
\hline & & & Knowledge Storage \\
\hline & & & $\begin{array}{l}\text { Knowledge } \\
\text { Absorption }\end{array}$ \\
\hline & & & Information system \\
\hline
\end{tabular}

Moreover, for the purpose of a better appreciation of the relationship dominating the factors confirmed in Delphi stages, this study has embarked on a survey of 55 large firms that are active in the Iranian food industry in order to describe the priorities and significance of the factors and the relationship among them. This is carried out through the construction of a questionnaire based on the extracted indices and then the distribution of the questionnaire in the sample population to which 43 firms have responded. Based on the statistical results, the weight regression of the factors- in accordance with the structural equations of the software, AMOS, are presented in Figure 2. 


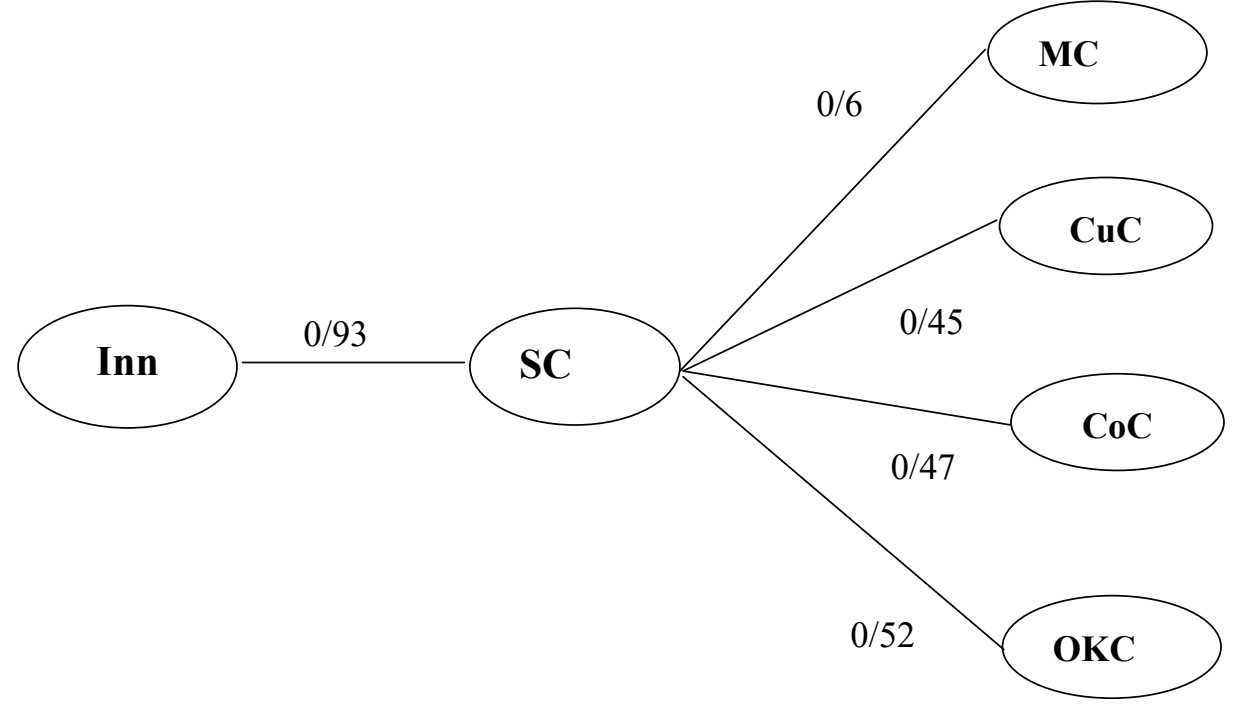

Figure 2. Structural Equation of the Model

In this figure, "Inn" is abbreviation of "Innovation Capability; "SC" is "Structural Capability"; "MC" is "Managerial Capacity"; "CuC" is "Cultural Capacity'; "CoC" is "Communicational Capacity" and "OKC" is "Organizational Knowledge Capacity". Figure 2 shows the structural capability can explain about 90 percent the innovation capability. It means the structural capability and its components could load on the innovation capability as main concept of the research. On the other hand, the list of the indices, based on the quantitative significance and priority of the mean, is provided in Table 5 . 
Table 5. Priority of Indices based on Industry comments

\begin{tabular}{|c|c|c|}
\hline Priority & Index & Component \\
\hline \multirow{8}{*}{1} & Management Style & Managerial Capacity \\
\hline & Risk Acceptance & Cultural Capacity \\
\hline & Knowledge Storage & $\begin{array}{l}\text { Organizational Knowledge } \\
\text { Capacity }\end{array}$ \\
\hline & Knowledge Absorption & $\begin{array}{l}\text { Organizational Knowledge } \\
\text { Capacity }\end{array}$ \\
\hline & Strategy And Goals & Managerial Capacity \\
\hline & Organizational Learning & $\begin{array}{l}\text { Organizational Knowledge } \\
\text { Capacity }\end{array}$ \\
\hline & Resource Availability & Managerial Capacity \\
\hline & Stability of Management & Managerial Capacity \\
\hline \multirow{3}{*}{2} & Information system & $\begin{array}{l}\text { Organizational Knowledge } \\
\text { Capacity }\end{array}$ \\
\hline & Communication Network & Communicative Capacity \\
\hline & Cooperation with others & Communicative Capacity \\
\hline \multirow{2}{*}{3} & Flexibility & Cultural Capacity \\
\hline & Diversity & Cultural Capacity \\
\hline
\end{tabular}

\section{Conclusion}

Recent research shows that one of the most dynamic capabilities that lead to strongest competitive advantage in the organizations is innovation capability. The innovation capability is connected with to other organizational capabilities. The innovation capability is defined as a great ability to provide innovative services and products continuously through the organizational capabilities and capacities.

This research focuses on the recognition of the structural facets of innovation capability and proposes a model of structural aspect of Innovation Capability. There are found to be four components under the Structural Capability. It is dependent on Managerial Capacity, Cultural Capacity, Communicative Capacity and Organizational Knowledge Capacity. In addition, this research identifies 13 indices as the most important elements which directly influence and are 
related to structural aspect of Innovation Capability.

According to the results obtained from prioritization based on the weight average of indexes, the management and leadership style of managers stemming from management capacity has the biggest role in the establishment and development of innovation capacity in the food industry organizations and firms. Of course, it is obvious that management and managerial decisions always furnish the ground for this important purpose but their assessment as the most significant factor in the food industry indicates the manager-centeredness of all theoretical and administrative processes in this industry.

Thus, it is recommended that senior managers and shareholders of food industry organizations and firms which are interested in the establishment and development of innovative capability take action to appoint and organize managers with non-authoritative and cooperative styles who have made extensive attempts regarding continuous innovation so that through this strategy, the most significant factor affecting the innovative capability may be at their service.

On the other hand, food industry has admitted that innovation is achieved in a cultural streamline. The risk acceptance aspect of culture which has attracted important studies in other fields plays an effective role in this regard. If food industry organization have the risk acceptance factor culture, they will possess a proper infrastructure for the establishment and development of innovative capability. Therefore, it is recommended that organizational culture should be oriented toward the development of risk acceptance. It is to be noted that cultural development takes time but if industry organizations ignore or neglect this, they will lose a fundamental infrastructure for innovation sooner or later.

Table 6. Formation of Structural Capability in Iran's Food Industry

\begin{tabular}{|l|l|}
\hline \multicolumn{2}{|c|}{ Structural Capability } \\
\hline Enhancement of Managerial Capacity & $\begin{array}{l}\text { Management and leadership style } \\
\text { (Non-authoritative and cooperative) }+ \\
\text { coordination of strategy and objectives + access } \\
\text { to financial and information sources + stability of } \\
\text { management }\end{array}$ \\
\hline Enhancement of cultural capacity & Risk acceptance \\
\hline $\begin{array}{l}\text { Enhancement of organizational knowledge } \\
\text { capacity }\end{array}$ & $\begin{array}{l}\text { Enhancement of organizational knowledge } \\
\text { capacity }\end{array}$ \\
\hline Enhancement of communication Capacity & Enhancement of communication capacity \\
\hline
\end{tabular}

This research aim at developing the innovation capability as a significant aspect of dynamic capabilities of an organisation. Organizations and companies can apply the suggested conceptual model to review their organisational innovation capability and to continuously improve their internal resources. 


\section{Al Macrothink}

Journal of Management Research ISSN 1941-899X 2016, Vol. 8, No. 2

The generic character of this study calls for further research in this research topic and in specific empirical domains. This research could investigate the practical implementation of the model and generate more specific recommends of how to apply this model in organizations and firms.

The most important limitation of the study is the impossibility of cooperative observation for the purpose of finding the capabilities in the industry. This is because the precise understanding of the nature of the capability requires cooperative observation by the researcher. Thus, this study has utilized alternative methods of data gathering. And with regard to the findings of this study, it seems that the most significant factor which can institutionalize the innovation capability in organizations is the management capacity. The management style, strategies, plans, decisions, etc. are very important in this regard. Therefore, the selection and appointments of the managers of firms and organizations is vital for the establishment and development of the innovation capability. Moreover, absorption and accumulation of organizational knowledge is another essential ground leading to the realization of innovation.

\section{References}

Bain, J. S. (1968). Industrial organization. (2nd ed.). New York: John Wiley \& Sons.

Bansal, P., \& Bogner, W.C. (2007). Knowledge management as the basis of sustained high performance. Journal of Management Studies, 44(1), 165-188. http://dx.doi.org/10.1111/j.1467-6486.2007.00667.x

Barney, J. B. (1986). Organizational Culture: Can It Be a Source of Sustained Competitive Advantage. Academy of Management Review, 11(3), 656-665.

Barney, J. B. (1991). Firm Resource and Sustained Competitive Advantage. Journal of Management, 17(1), 99-120. http://dx.doi.org/10.1177/014920639101700108

Bhattacherjee, Anol (2012). Social Science Research: Principles, Methods and Practices. Florida: Creative Commons Attribution Publications.

Börjesson, Sofia, \& Elmquist, Maria (2011). Developing Innovation Capabilities: A Longitudinal Study of a Project at Volvo Cars. Creativity and Innovation Management, 20(3), 176-177. http://dx.doi.org/10.1111/j.1467-8691.2011.00605.x

Cassiman, B., \& Veugelers, R. (2006). In search of complementarity in innovation strategy: internal R\&D and external knowledge acquisition. Management Science, 52(1), 68-82. http://dx.doi.org/10.1287/mnsc. 1050.0470

Chesbrough, Henry (2006). Open Business Models: How to Thrive in the New Innovation Landscape. Boston: Harvard Business School Press.

Chiesa, V., Coughlan, P., \& Voss, C. A. (1996). Development of a technical innovation audit. Journal of Product Innovation Management, 13(2), 105-136. http://dx.doi.org/10.1111/1540-5885.1320105 
Colarelli O'Connor, G. (2008). Major Innovation as a Dynamic Capability: A Systems Approach. Journal of Product Innovation Management, 25(4), 313-30. http://dx.doi.org/10.1111/j.1540-5885.2008.00304.x

Colarelli O’Connor, G., \& DeMartino, R. (2006). Organizing for Radical Innovation: An Exploratory Study of the Structural Aspects of Management Systems in Large Firms. Journal of Product Innovation Management, 23(6), 475-97. http://dx.doi.org/10.1111/j.1540-5885.2006.00219.x

Crook, T. R., Ketchen Jr, D. J., Combs, J. G., \& Todd, S. Y. (2008). Strategic resources and performance: a meta-analysis. Strategic Management Journal, 29(11), 1141-1154. http://dx.doi.org/10.1002/smj.703

De Marchi, Valentina (2010). Cooperation toward Environmental Innovation: An Empirical Investigation. University of Padua, Working Paper No 119. http://dx.doi.org/10.2139/ssrn. 1677277

Eisenhardt, K.M., \& Martin, J.A. (2000). Dynamic Capabilities: What Are They?. Strategic Management Journal, 21(10/11), 1105-1121.

Fidler, Lori A., \& Johnson J. David (1984). Communication and Innovation Implementation. The Academy of Management Review, 9(4), 704-711.

Grant, R., \& Baden-Fuller, C. (2004). A knowledge accessing theory of strategic alliances. Journal of Management Studies, 41(1), 61-84.

Guan, J., \& Ma, N. (2003). Innovative capability and export performance of Chinese firms. Technovation Journal, 23(9), 737-747.

Hage, J. T. (1999). Organizational Innovation capability and Organizational Change. Annual Reviews of Sociology, 25, 597-622.

Helfat, C.E., \& Peteraf, M.A. (2003). The Dynamic Resource Based View: Capability Lifecycles. Strategic Management Journal, 24(10), 997-1010. http://dx.doi.org/10.1002/smj.332

Helfat, C.E., Finkelstein, S., Mitchell, W., Peteraf, M., Singh, H., Teece, D., \& Winter S., (2007). Dynamic Capabilities: Understanding strategic change in organizations. LondonOxford: Blackwell, pp. 30-45.

Hii, J., \& Neely, A. (2000). Innovative capacity of firms: on why some firms are more innovative than others. 7th International Annual EurOMA Conference, 7, Ghent, Proceedings, Belgium. http://dspace.lib.cranfield.ac.uk/handle/1826/3788

Hung, R.Y., Yang, B., Lien, B., McLean, G.N., \& Kuo, Y. (2010). Dynamic capability: Impact of process alignment and organizational learning culture on performance. Journal of World Business, 45(3), 285-294. http://dx.doi.org/10.1016/j.jwb.2009.09.003

Khalil, Taregh (2002). Technology Management. Translated by Mohamad Arabi \& Davood Eizadi, Tehran: Cultural Research's Office Pub. pp. 26-45. 
Kodam, Mitsuru, \& Shibata, Tomoatsu (2014). Strategy transformation through strategic innovation capability: a case study of Fanuc. $R \& D$ Management Journal, 44(1), 75-103. http://dx.doi.org/10.1111/radm.12041

Lam, Alice (2004). Organizational Innovation, Brunel University, Brunel Research in Enterprise, Innovation capability, Sustainability and Ethics. Working paper No 1. https://mpra.ub.uni-muenchen.de/11539/

Lane, P. J., Koka, B. R., \& Pathak, S. (2006). The reification of absorptive capacity: a critical review and rejuvenation of the construct. Academy of Management Review, 31(4), 833-863. http://dx.doi.org/10.5465/AMR.2006.22527456

Lawson, Benn, \& Samson, Danny (2001). Developing Innovation Capability in organizations: a dynamic capability approach. International Journal of Innovation Management, 5(3), 377-400. http://dx.doi.org/10.1142/S1363919601000427

Lichtenthaler, Ulrich (2007). The drivers of technology licensing: an industry comparison. California Management Review, 49(4), 67-89. http://dx.doi.org/10.2307/41166406

Lichtenthaler, Ulrich, \& Lichtenthaler, Eckhard (2009). A Capability Based Framework for Open Innovation: Complementing Absorptive Capacity. Journal of Management Studies, 46(8), 1315- 1338. http://dx.doi.org/10.1111/j.1467-6486.2009.00854.x

Lichtenthaler, Ulrich, \& Muethel, Miriam (2012). The Impact of Family Involvement on Dynamic Innovation Capabilities: Evidence from German Manufacturing Firms. Journal of Entrepreneurship Theory and Practice, 36(6), 1235-1253. http://dx.doi.org/10.1111/j.1540-6520.2012.00548.x

Maxwell, Joseph A. (2013). Qualitative inquiry and research design: Choosing among five approaches. (3rd ed.). New York: SAGE Publications.

Okoli, Chitu, \& Pawlowski, Suzanne D. (2004). The Delphi method as a research tool: an example, design considerations and applications. Information and Management Journal, 42(1), 15-29. http://dx.doi.org/10.1016/j.im.2003.11.002

Porter, Michael E. (1980). Competitive Advantage: Techniques for Analyzing Industrial and Competitors. New York: Free Press.

Sáenz, J., Aramburu, N., \& Rivera, O. (2009). Knowledge sharing and innovation performance; a comparison between high tech and low tech companies. Journal of Intellectual Capital, 10(1), 22- 36. http://dx.doi.org/10.1108/14691930910922879

Saunila, Minna, \& Ukko, Juhani (2012). A Conceptual Framework for the Measurement of Innovation Capability. Baltic Journal of Management, 7(4), 355-375. http://dx.doi.org/10.1108/17465261211272139

Saunila, Minna, Ukko, Juhani, \& Rantanen, Hannu (2014). Does Innovation Capability Really Matter for the Profitability of SMEs?. Knowledge and Process Management, 21(2), 134 -142. http://dx.doi.org/10.1002/kpm.1442 


\section{Macrothink}

Journal of Management Research

ISSN 1941-899X 2016, Vol. 8, No. 2

Skiltere, Daina, \& Jesilevska, Svetlana (2013). Building the System of Innovation Capability Indicators: Case of Latvia. Eurasian Journal of Business and Economics, 6 (12), 113-128.

Teece, David J. (2009). Dynamic Capabilities and Strategic Management: Organizing for Innovation and Growth. London: Oxford University Press. pp. 18-33.

Teece, David J. (2006). Reflections on Profiting from Innovation. Research Policy, 35(8), 1131-1146. http://dx.doi.org/10.1016/j.respol.2006.09.009

Teece, D. J., Pisano, G., \& Shuen, A. (1997). Dynamic capabilities and strategic management. Strategic Management Journal, 18 (7), 509-533.

Tidd, J., Bessant, J., \& Pavitt, K. (2005). Managing Innovation, Integrating Technological, Market and Organizational Change. (3rd ed.). New York: John Wiley \& Sons.

Verma, P., Singh, B. \& Rao, M.K. (2014). Developing Innovation Capability: The Role of Organizational Learning Culture and Task Motivation. Global Journal of Finance and Management, 6(6), 575-582.

Zawislak, P.A., Alves, A., Gamarra, J., Barbieux, D., \& Reichert, F. (2012). Innovation Capability: From Technology Development to Transaction Capability. Journal of Technology $\begin{array}{llll}\text { Management } \quad \text { Innovation, } & \text { 14-27. }\end{array}$ http://dx.doi.org/10.4067/S0718-27242012000200002

Zawislak, P.A., Alves, A., Gamarra, J., Barbieux, D., \& Reichert, F. (2013). Influences of the Internal Capabilities of Firms on their Innovation Performance: A Case Study Investigation in Brazil. International Journal of Management, 30 (1), 329-348.

Zollo, M., \& Winter, S. G. (2002). Deliberate learning and evaluation of dynamic capabilities. Organization Science, 13(3), 339-351. http://dx.doi.org/10.1287/orsc.13.3.339.2780 